\title{
Photocatalytic Water Purification with ZnO Thin Films in Demineralized as Well as Natural Waters
}

\section{Grivel, JeanClaude}

\section{Published in:}

Physica Status Solidi - A - Applications and Materials Science

Link to article, DOI:

10.1002/pssa.201800880

Publication date:

2019

Document Version

Peer reviewed version

Link back to DTU Orbit

Citation (APA):

Grivel, JC. (2019). Photocatalytic Water Purification with ZnO Thin Films in Demineralized as Well as Natural Waters. Physica Status Solidi - A - Applications and Materials Science, 216(44), [1800880].

https://doi.org/10.1002/pssa.201800880

\section{General rights}

Copyright and moral rights for the publications made accessible in the public portal are retained by the authors and/or other copyright owners and it is a condition of accessing publications that users recognise and abide by the legal requirements associated with these rights.

- Users may download and print one copy of any publication from the public portal for the purpose of private study or research.

- You may not further distribute the material or use it for any profit-making activity or commercial gain

- You may freely distribute the URL identifying the publication in the public portal 
See discussions, stats, and author profiles for this publication at: https://www.researchgate.net/publication/332204282

\section{Photocatalytic Water Purification with ZnO Thin Films in Demineralized as Well as Natural Waters}

Article in Physica status solidi · April 2019

DOI: $10.1002 /$ pssa.201800880

CITATIONS

READS

0

98

1 author:

Jean-Claude Grivel

Technical University of Denmark

243 PUBLICATIONS 2,442 CITATIONS

SEE PROFILE

Some of the authors of this publication are also working on these related projects:

Project Ternary oxide phase equilibria View project

Substrates for coated conductors View project 
Physica Status Solidi A / Accepted / DOI: 10.1002/ ((jssa.201800880))

Title: Photocatalytic water purification with $\mathrm{ZnO}$ thin films in demineralised as well as natural waters Author(s), and Corresponding Author(s)* Jean-Claude Grivel*

J.-C. Grivel

Technical University of Denmark, Department of Energy Conversion and Storage, Frederiksborgvej 399, DK-4000 Roskilde, Denmark

E-mail: jean@dtu.dk

Keywords: ZnO, photocatalysis, methylene blue, water cleaning, films

\begin{abstract}
$\mathrm{ZnO}$ films prepared on glass plates using a water based coating solution are characterized and tested for methylene blue dye photocatalytic decolourisation in various types of waters (demineralised water, seaand lake-water). The influence of various parameters such as wavelength and attenuation of incident radiation by dye and/or organic matter is studied. In demineralised water, up to $90 \%$ decoloration was achieved within $1 \mathrm{~h}$ with $365 \mathrm{~nm}$ irradiation on a $10 \mathrm{ml}$. Although the $\mathrm{ZnO}$ films still show some activity when illuminated by standard visible light lamps, the efficiency of the photocatalytic process is greatly reduced. Natural waters result in a significant decrease of the photocatalytic activity, under both UV and visible light irradiation. The main factor is believed to be enhanced UV light absorption within the liquid. The influence of organic and mineral matter in natural waters is briefly discussed.
\end{abstract}

\title{
1. Introduction
}

The increasing contribution of emerging pollutants to water quality degradation is becoming a matter of serious concern. For example, the recent UNESCO report on the discharge of pharmaceutical products in the aquatic environment of the Baltic Sea region reveals the presence of more than 100 pharmaceuticals that are not efficiently removed from wastewater by municipal wastewater treatment plants. ${ }^{[1]}$ This results in an annual release of about 1.8 thousand tons of pharmaceuticals in the environment every year just in this restricted area of the world. Among several new treatments, which are under development in order to mitigate this worrisome situation, the mineralization of pollutant molecules by means of photocatalysis appears as a promising solution. In this type of processes, an electron-hole pair is created in a semiconducting material upon irradiation with ultraviolet (UV) or visible light. Both charge carriers can interact directly or indirectly with pollutant molecules adsorbed on the surface of the semiconductor, splitting these molecules into smaller fragments and hopefully ending with harmless compounds. Zinc oxide $(\mathrm{ZnO})$ is an interesting semiconducting material for photocatalytic water purification and has been the subject of many studies. ${ }^{[2-7]}$ Although its large scale use still suffers from important limitations such as limited efficiency under visible light due to a band gap of about 3.2-3.4 eV and photocorrosion ${ }^{[8-11]}$, recent developments have demonstrated that ZnO nanoparticles have a tremendous potential for water purification applications using a photocatalytic approach, which is simpler than a photoelectrocatalytic process $^{[12-14]}$. Furthermore, $\mathrm{ZnO}$ has the benefits of being cheap and mechanically stable. For 
environmental applications however, the use of nanoparticles is not the optimal solution, since the particles need to be reclaimed from the treated water after use and $\mathrm{ZnO}$ nanoparticles are not without dangers for ecological receptors ${ }^{[15-18]}$ although it is often claimed that $\mathrm{ZnO}$ is non-toxic. Thin films would be more appropriate, because the photocatalytic material remains fixed and can be removed by redrawing the film from the treated water. The photocatalytic activity of $\mathrm{ZnO}$ thin films has been less studied than that of nanoparticles, although some research teams have already reported results on the photocatlytic degradation of a variety of dyes such as malachite green, reactive black, orange II, rhodamine B, rose bengal and methylene blue on $\mathrm{ZnO}$ films [19-23]. These studies are usually performed using pure-water-based dye solutions. However, to tackle the problem of environmental pollution and its remediation, studies of photocatalytic degradation of dyes in natural waters are also needed. The purpose and novelty of the present work is to obtain preliminary data for assessing the influence of the latter on the efficiency of $\mathrm{ZnO}$ films, using the industrial dye methylene blue trihydrate as a case study.

\section{Results and discussion}

\subsection{Films characterization}

Figure 1 shows the thermogravimetric (TG) trace recorded upon heating a $9.3 \mathrm{mg}$ sample of dried precursor solution consisting initially of a solution of zinc acetate and polyvinyl alcohol (PVA) in deionized water. It shows a first, sharp mass loss between $200^{\circ} \mathrm{C}$ and $250^{\circ} \mathrm{C}$, which amounts to about $50 \%$ of the starting sample mass. It is followed by a slower mass loss that is finished at $480^{\circ} \mathrm{C}$ with a total mass loss of $72 \%$ (i.e. $\approx 22 \%$ for the second mass loss). These two temperature ranges correspond well to those reported for the thermal decomposition of $\mathrm{Zn}$-acetate ${ }^{[24]}$ and $\mathrm{PVA}^{[25]}$ respectively. Furthermore, the theoretical mass loss values are expected in the intervals $43 \%$ - 52\% for $\mathrm{Zn}$ acetate and $20 \%$ - 23\% for PVA depending on the degree of hydration of $\mathrm{Zn}$-acetate in the powder. These values are in good agreement with the observed mass losses. The fact that $\mathrm{ZnO}$ forms within the PVA matrix prior to the disappearance of the latter at higher temperature is expected to be favorable for limiting the grain growth of $\mathrm{ZnO}$. 


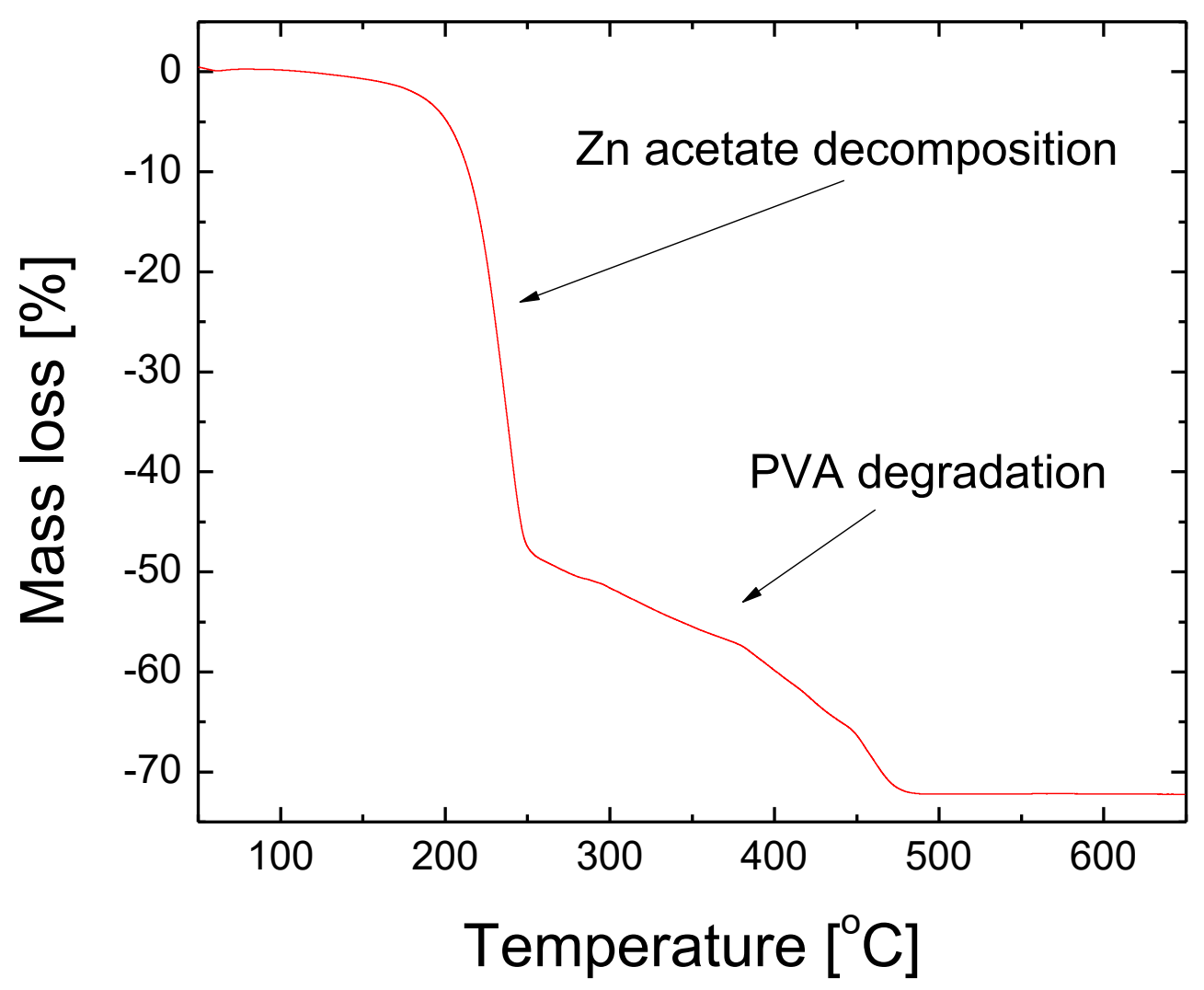

Figure 1. TG measurement of the dried precursor solution in air (heating rate: $5^{\circ} \mathrm{C} / \mathrm{min}$ ).

The XRD pattern of a $\mathrm{ZnO}$ film deposited on a glass plate and after heat treatment at $600^{\circ} \mathrm{C}$ is shown in the inset of Figure $\mathbf{2} \mathbf{b}$. There is an amorphous background coming from the glass substrate but diffraction peaks corresponding to ZnO (hexagonal, wurtzite form) are clearly seen. For random crystallite orientation, the peak appearing at $2 \theta=36.1^{\circ}$ (Miller indices (101)) would have about twice the intensity of those at $31.6^{\circ}(100)$ and $34.3^{\circ}(002)$. Therefore it can be concluded that some preferential orientation is present in the $\mathrm{ZnO}$ films, although only to a rather limited extent. The full width at half maximum of these three peaks can be used for estimating the $\mathrm{ZnO}$ grain size $D$ based on the Scherrer equation:

$$
D=\frac{0.9 \lambda}{\beta \cos \theta}
$$

Where $\lambda$ is the wavelength of the incident CuK $\alpha$ radiation (1.54 $\AA$ ), 6 is the full width at half maximum of the diffraction peaks expressed in radians after subtraction of the instrumental line broadening determined using Si standard powders and $\vartheta$ is the Bragg angle of the diffraction peak. The average result 
is $140 \pm 20 \mathrm{~nm}$. The films heated to $600^{\circ} \mathrm{C}$ indeed show a fine microstructure with particles around $100-$ $300 \mathrm{~nm}$ size as revealed in the SEM picture presented in Figure $\mathbf{2} \mathbf{b}$.

The UV-Vis absorption spectrum of a ZnO film deposited on glass (Figure 2a), shows an absorption threshold close to $400 \mathrm{~nm}$, with an absorption peak around $370 \mathrm{~nm}$, as usually reported for ZnO. ${ }^{\text {[26-32] }}$ Using a tauc plot (inset in Fig.2a), a band gap of $3.21 \pm 0.05 \mathrm{eV}$ was found, a value in agreement with previously published data for ZnO films. ${ }^{[12,13]}$
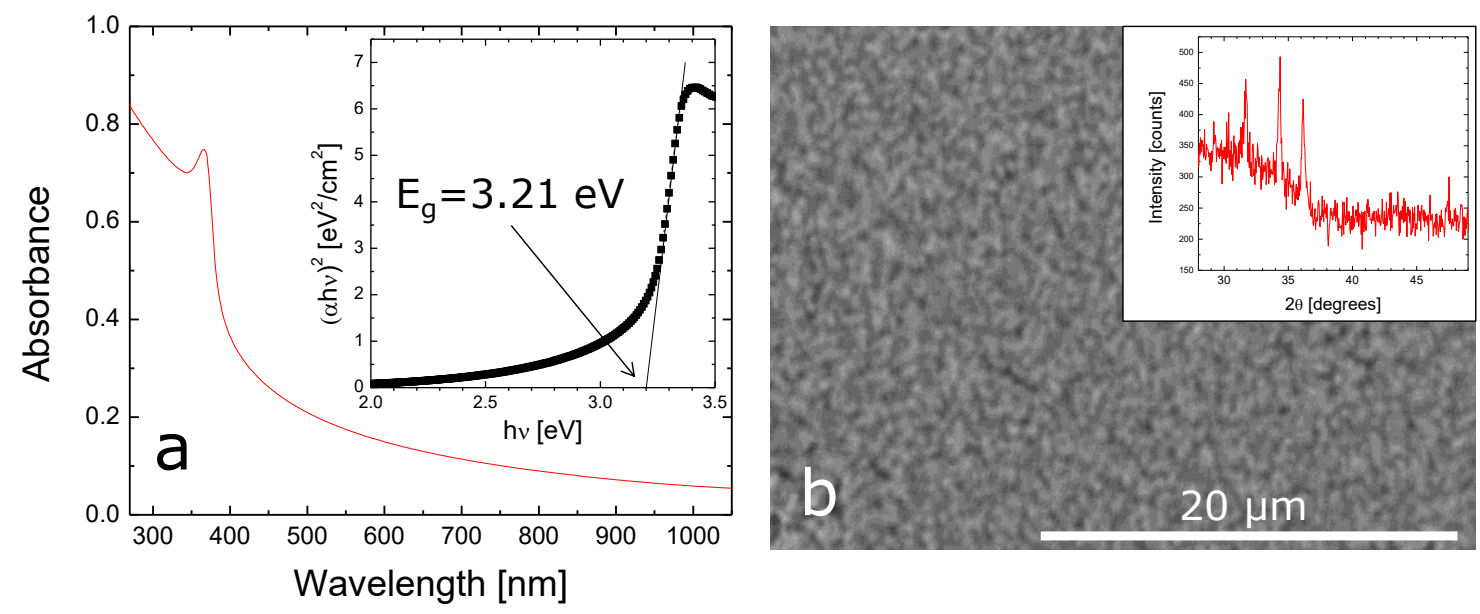

Figure 2. (a) UV-Vis absorption spectrum of a ZnO film on glass (inset: tauc plot indicating a band gap of $3.21 \mathrm{eV}$ ). (b) SEM image (backscattering mode) of a ZnO film showing grains with diameters lower than $200 \mathrm{~nm}$ (inset: XRD pattern of the film. The reflections correspond to $\mathrm{ZnO}$ and reveal a partial texture).

\subsection{Photocatalytic decolorization of methylene blue solutions}

Figure 3a illustrates the decolorization of methylene blue solutions in deionized water versus time under UV irradiation with two different wavelengths, i.e. $311 \mathrm{~nm}$ and $365 \mathrm{~nm}$ and three different volumes of liquid while the surface area of the $\mathrm{ZnO}$ film was fixed at $19 \mathrm{~cm}^{2}$ for all experiments. Whereas the wavelength of the incident radiation has no influence on the decolorization rate, decreasing the volume of the methylene blue solution results in a clear acceleration of the process. This is most likely a result of the increased ratio between film surface area and solution volume rather than an effect due to UV absorption by the solution itself. In fact, although the liquid height varies from $2.5 \mathrm{~mm}$ for $10 \mathrm{ml}$ solution to $10 \mathrm{~mm}$ for $40 \mathrm{ml}$, no changes in the intensity of the incident UV radiation is taking place. The latter (950 $\pm 10\left[\mu \mathrm{Wcm}^{-2}\right]$ ) is estimated by placing the radiometer below the liquid holder and progressively adding more solution. No intensity decrease within the measuring accuracy of the measuring instrument is observed up to the maximum tested liquid height ( $12.5 \mathrm{~mm}$, corresponding to $50 \mathrm{ml}$ solution). 

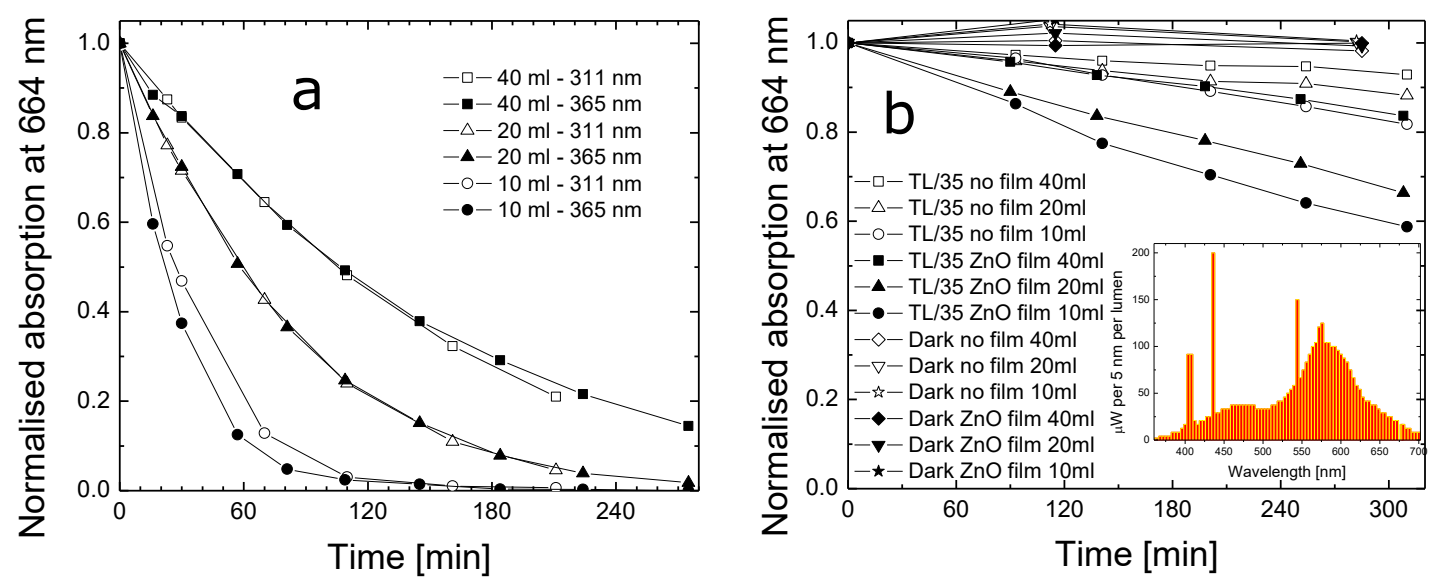

Figure 3. (a) Methylene blue decolorization in deionized water solutions under irradiation with two different UV wavelengths. (b) Methylene blue decolorization under two standard Philips TL/35 light bulbs (emmission spectrum based on supplier's data in the inset - 2000 Lux intensity at liquid surface) as well as results of measurements in the dark.

Figure $\mathbf{3 b}$ shows the results of decolorization experiments conducted using a standard TL/35 Philips lamp, whose emission spectrum, redrawn from the supplier's data is shown in the inset of Figure 3b. The decolorization speed is obviously much reduced compared with irradiation with the UV source. Comparison with measurements performed without $\mathrm{ZnO}$ films but otherwise similar conditions (photolysis) shows a measurable albeit weak decolorization effect. Nevertheless, the ZnO films clearly accelerate the degradation effect. Contrary to the case of UV irradiation, the intensity of the visible light reaching the $\mathrm{ZnO}$ film is greatly reduced by absorption taking place in the methylene blue solution. The attenuation rate amounts to $85 \mathrm{Lux}(4.2 \%)$ per $\mathrm{mm}$ of liquid lying above the film. There is however some measurable UV irradiation coming from the lamps corresponding to a power density of $3.5 \mu \mathrm{W} \mathrm{cm}{ }^{-2}$ that is not affected by the presence of the methylene blue solution. It can be assumed that the observed decolorization of the solutions is mostly due to this weak UV contribution since the band gap of the $\mathrm{ZnO}$ films $(\approx 3.2 \mathrm{eV}$ ) corresponds to a wavelength of $387 \mathrm{~nm}$ so that only a tiny amount of the radiation can be harvested.

Figure 4 demonstrates the effect of changing from deionized water to natural sea water on the decolorization speed of methylene blue solutions under UV irradiation. Obviously, the decrease of methylene blue absorbance level takes place at a remarkably slower pace in the present case. Using lake water instead of sea water yields similar results, which are therefore not shown here. Measurements conducted without $\mathrm{ZnO}$ films even show a monotonic increase of the absorbance during the $6.5 \mathrm{~h}$ runs. This effect can be attributed to slow evaporation $\mathrm{H}_{2} \mathrm{O}$ under the effect of UV irradiation, which results in a progressive increase of the methylene blue concentration in the solutions. Considering the fact that the $\mathrm{pH}$ of natural waters (8.2 in the present cases) is much higher than that of deionized water (5.5), the significantly slower decolorization rate may appear surprising. Indeed, previous reports demonstrated that increasing the $\mathrm{pH}$ of methylene blue solutions by addition of $\mathrm{NaOH}$ results in an increased decolorization rate with optimum around $8-11 .{ }^{[23,31,32]}$ This effect is related to the fact that methylene blue 
is a cationic dye so that its adsorption on the surface of $\mathrm{ZnO}$ (point of zero charge between 8.9 and 10.2) ${ }^{[34-}$ ${ }^{36]}$ is favored at high $\mathrm{pH}$ where the surface of $\mathrm{ZnO}$ becomes less positively or even negatively charged.

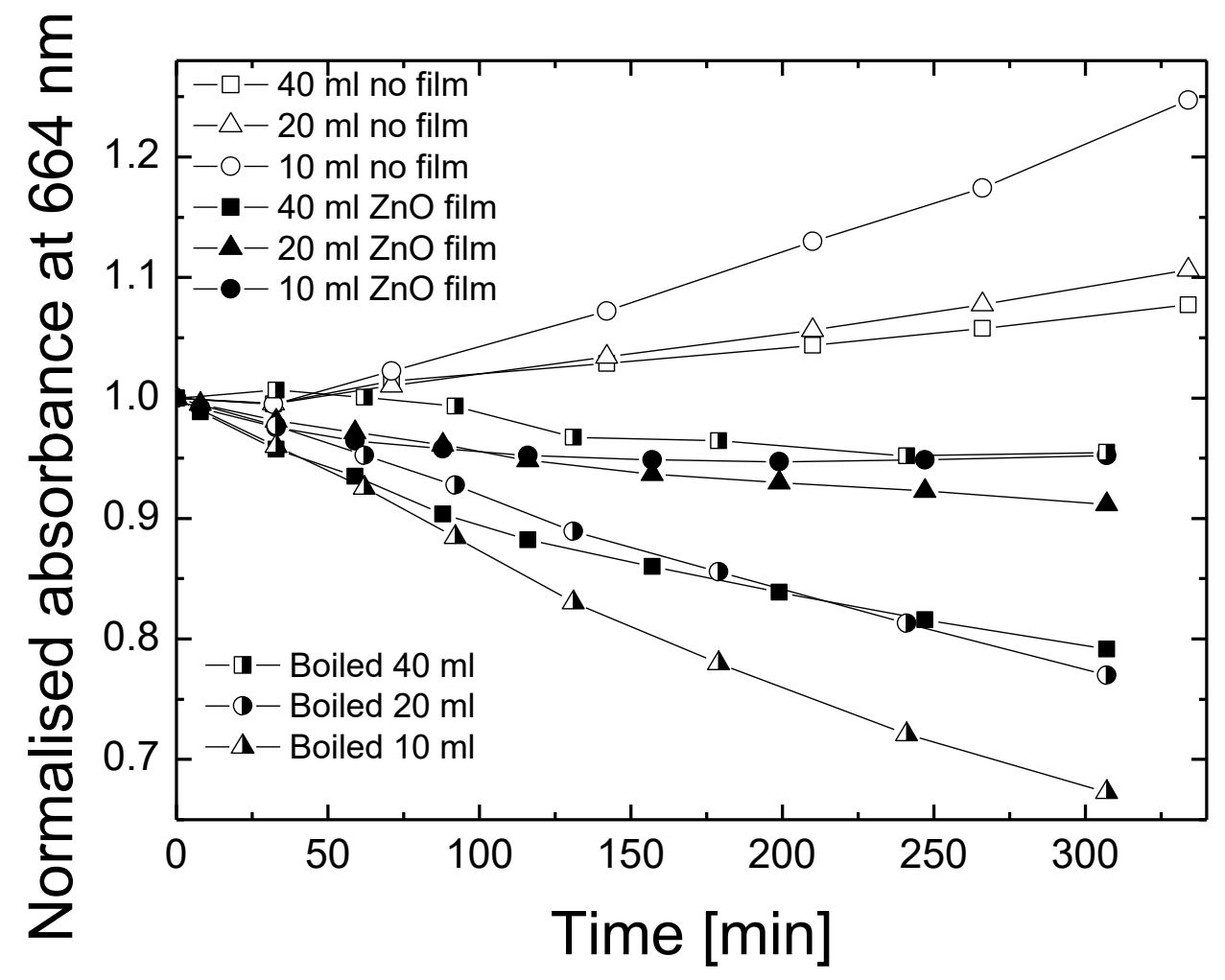

Figure 4. Methylene blue decolorization under irradiation with a $365 \mathrm{~nm}$ UV source. The solvent consisted of sea water collected in the Baltic Sea near the city of Roskilde in Denmark ( $\mathrm{pH}=8.2$ ). The water was used either as collected or after boiling. Data for experiments with fresh sea water without ZnO films (photolysis) are also included. Inset: intensity of the UV irradiation ( $365 \mathrm{~nm}$ ) reaching the film, versus the distance between the film and the water surface.

However, an additional effect plays an important role in natural waters: the absorbance in the near UV range is much higher than for deionized water. This is illustrated in Figure 5, where the UV-Vis absorption spectrum of deionized $\mathrm{H}_{2} \mathrm{O}$ is compared to the absorption of natural water samples of two different origins, i.e. collected in the Baltic Sea and in the Avns $\varnothing$ lake. This enhanced absorption, which results in a yellowish color, reduces the intensity of the UV irradiation reaching the ZnO film and thereby decreases the efficiency of the photocatalytic decolorization process. 


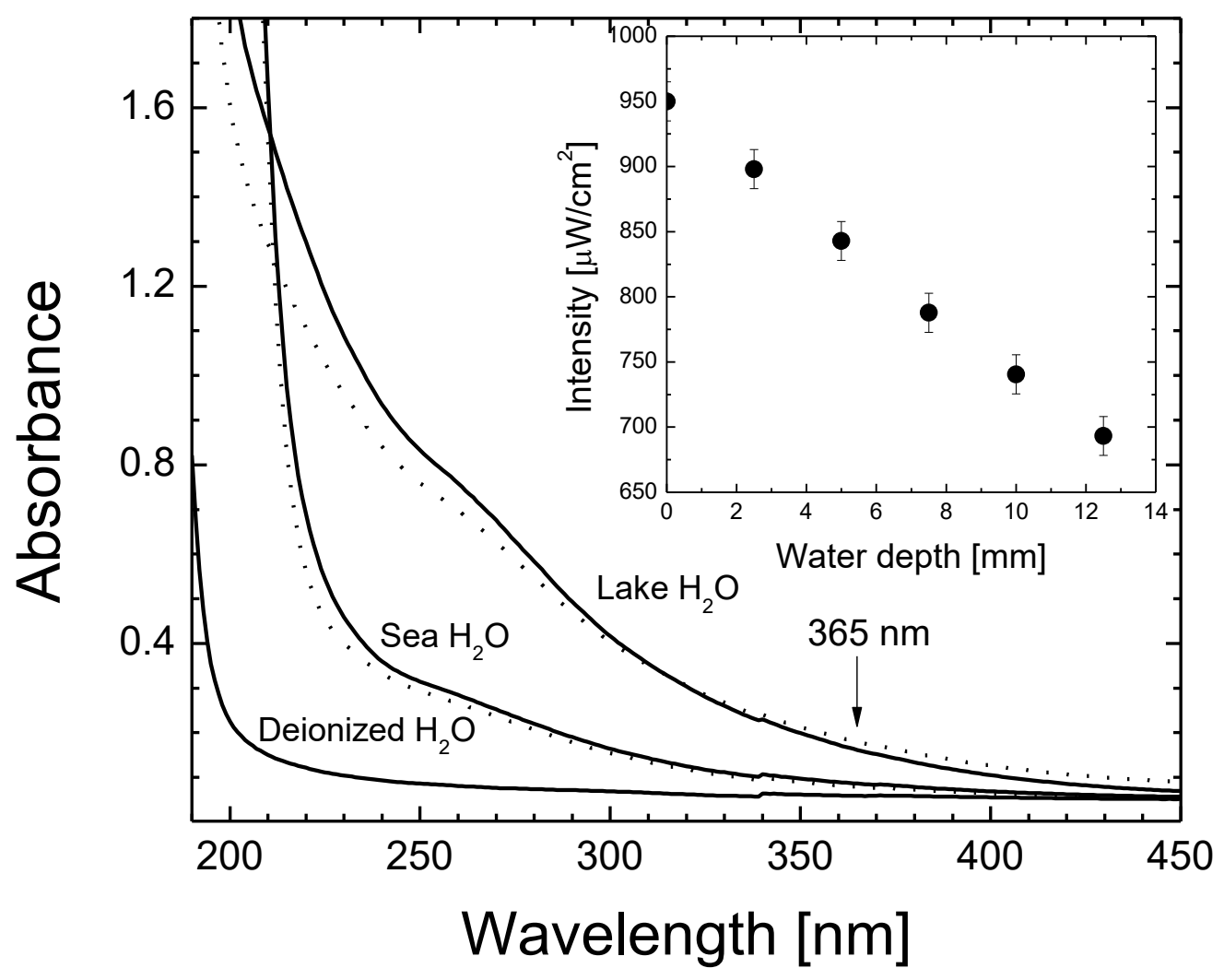

Figure 5. UV-Vis absorbance of the three kinds of waters used for the photocatalytic decomposition of methylene blue trihydrate. For the natural waters (sea and lake), the dotted line represents the measurements performed after boiling. Inset: intensity of the UV irradiation $(365 \mathrm{~nm})$ reaching the film, versus the distance between the film and the water surface.

A sterilization treatment was applied by boiling the natural waters during one hour under reflux. This resulted in the decantation of at least a part of the microorganisms that deposited on the bottom of the glass beaker during cooling. Nevertheless, the yellowish color subsisted, with limited changes in the UV absorption of the waters under study and only a slight improvement of the decolorization rate of the methylene blue solution can be observed for the $10 \mathrm{ml}$ and $20 \mathrm{ml}$ solution volumes. For the $40 \mathrm{ml}$ sample, a worsening is even observed. A possible explanation for this difference might be that sedimentation of dead microorganisms continues at a decreasing rate during several hours after boiling so that the $\mathrm{ZnO}$ films are progressively partially covered with inert matter that absorbs UV radiation and/or prevents methylene blue molecules of adsorbing on the surface of $\mathrm{ZnO}$ particles. This effect is expected to be enhanced with a larger solution volume or more specifically with an increase of the height of liquid lying above the $\mathrm{ZnO}$ film. This hypothesis however needs to be confirmed by further experiments. Other phenomena due to e.g. dissolved ionic species, $\mathrm{Na}^{+}$or $\mathrm{Cl}^{-}$ions present in sea water, formation of a biofilm on the surface of the $\mathrm{ZnO}$ film, etc. may also be at play in natural waters and result in effects that are significantly different from those taking place in deionized water. These observations underscore the 
importance of not restricting the study of photocatalytic pollutant degradation to solutions made with pure water, because natural water can result in significantly different effects.

\section{Conclusion}

Using nanostructured $\mathrm{ZnO}$ films deposited on glass substrates using a green chemical solution deposition technique, it is shown that decolorization of methylene blue solutions upon $365 \mathrm{~nm}$ UV irradiation is more efficient in deionized than natural water under similar conditions. Visible light only results in slow decolorization but using an incident wavelength shorter than $365 \mathrm{~nm}$ does not accelerate the process. The ratio of the film surface to liquid volume plays a critical role in the decolorization kinetics. With visible light irradiation, this is partly due to light attenuation by absorption in the solution, an effect that is not significant for $365 \mathrm{~nm}$ irradiation in deionized water. Natural waters instead show an enhanced absorption in the UV range. The significant difference of decolorization kinetics taking place when natural water is used can have various origins, which deserve further studies. This effect can have very important implications for the potential use of $\mathrm{ZnO}$ photocatalyst films if they are intended to be used for remediation actions in case of accidental spillage of emerging pollutants in the environment.

\section{Experimental Section}

\subsection{Film preparation}

For manufacturing the $\mathrm{ZnO}$ films $10 \mathrm{~g} \mathrm{Zn-acetate} \mathrm{dihydrate} \mathrm{(BDH} \mathrm{Chemicals} \mathrm{Ltd)} \mathrm{are} \mathrm{dissolved} \mathrm{in} 50 \mathrm{ml}$ demineralized $\mathrm{H}_{2} \mathrm{O}$, followed by the addition of $2.5 \mathrm{~g}$ polyvinyl alcohol (PVA - Alfa Aesar, 98-99\%, hydrolyzed, low molecular weight). The substrates consist of microscope glass slides (Brand $\mathrm{GmbH}$ ) that are cleaned with ethanol and methanol prior to coating. Spin coating is performed with a VTC-100 instrument from MTI Corporation at a spinning rate of $2000 \mathrm{rpm}$ during $30 \mathrm{~s}$. The films (single coating) are first dried at $50^{\circ} \mathrm{C}$ on a hot plate for $10 \mathrm{~min}$. Conversion to $\mathrm{ZnO}$ is conducted under oxygen flow in a tube furnace at $600 \pm 5^{\circ} \mathrm{C}$ during $0.5 \mathrm{~h}$, with $2{ }^{\circ} \mathrm{C} / \mathrm{min}$ heating rate and furnace cooling. After heat treatment, the amount of deposited $\mathrm{ZnO}$ amounts to $70 \mu \mathrm{g} / \mathrm{cm}^{2}$.

\subsection{Characterization}

The precursor decomposition is investigated by simultaneous thermogravimetry and differential thermal analysis (TG-DTA) using a Netzsch 449 STA instrument at a heating rate of $2^{\circ} \mathrm{C} \mathrm{min}^{-1}$ under oxygen flow. The sample consists of powders obtained by slowly evaporating $\mathrm{H}_{2} \mathrm{O}$ from a few $\mathrm{ml}$ of coating solution and drying it on a hot plate at $50{ }^{\circ} \mathrm{C}$. The microstructure of the film is studied by scanning electron microscopy (Hitachi TM3000). It is further characterized by UV-Vis spectroscopy (VWR UV-3100PC) and X-ray diffraction (Bruker D8 with Cu Ka radiation).

\subsection{Photocatalysis experiments}

The dye solution is made using methylene blue trihydrate $\left(\mathrm{C}_{16} \mathrm{H}_{18} \mathrm{ClN}_{3} \mathrm{~S} \cdot 3 \mathrm{H}_{2} \mathrm{O}\right.$ from Alfa Aesar, assay $100.4 \%$ - anhydrous basis). The concentration of the solutions is $5 \mathrm{ppm}$, in either deionized water or surface water collected from the Baltic Sea in the Roskilde Fjord $\left(55.69^{\circ}\right.$ North, $12.09^{\circ}$ East) or in a lake (Avns $\varnothing$ ) situated on the Sjælland island (55.57 $7^{\circ}$ North, $11.89^{\circ}$ East). The irradiation source consists of either a UV lamp 
(UVP, 8W from Analytic Jena, $\lambda=365$ or $311 \mathrm{~nm}$ ), or a pair of standard Philips TL/35 light tubes. The volume of the tested solution varies from $10 \mathrm{ml}$ to $40 \mathrm{ml}$ depending on the experimental protocol. It is placed in a polyethylene box with rectangular shape $\left(50 \times 70 \mathrm{~mm}^{2}\right.$ internal surface area dimensions) with the $\mathrm{ZnO}$ films ( $19 \mathrm{~cm}^{2}$ area) placed in the bottom of the boxes. The surface of the liquid is located about $12 \mathrm{~cm}$ below the UV lamp or $70 \mathrm{~cm}$ below the TL/35 light tubes resulting in a power density at the liquid surface of $950 \pm 10 \mu \mathrm{W} \mathrm{cm}{ }^{-2}$ for the UV lamp (as measured with a UVX radiometer from Analytik-Jena AG) and an illuminance of 2000 Lux (Traceable ${ }^{\circledR}$ Light meter) for the visible light irradiation. Magnetic stirring is applied during the experiments. The $1.5 \mathrm{ml}$ of the solution are redrawn for UV-Vis absorption during the course of the experiments and poured back in their respective holders after measurements in order to avoid decreasing the volume of liquid. The decolorization of the solution is followed by plotting the intensity of the absorbance at $664 \mathrm{~nm}$ (maximum absorbance of methylene blue) versus irradiation time after normalizing with the intensity at $\mathrm{t}=0$. Prior to switching the lamps on, the solution is left in contact with the films in the holders during $1 \mathrm{~h}$ to reduce the influence of adsorption effects on the solution decolorization. The experiments performed with the methylene blue solution in deionized water and UV irradiation were conducted 3 times in a raw with the same films merely rinsed with deionized water in between. The results were reproducible within $5 \%$.

\section{Conflict of Interest}

The author has no financial/commercial Conflict of Interest.

\section{Acknowledgements}

This work was financed by the Technical University of Denmark.

Received: ((will be filled in by the editorial staff))

Revised: ((will be filled in by the editorial staff))

Published online: ((will be filled in by the editorial staff))

\section{References}

[1] UNESCO, Pharmaceuticals in the aquatic environment of the Baltic Sea region: A status report, http://unesdoc.unesco.org/images/0024/002478/247889e.pdf, accessed November, 2018.

[2] M. Pirhashemi, A. Habibi-Yangjeh, S. Rahim Pouran J. Industr. Eng. Chem. 2018, 62, 1

[3] C.B. Ong, L.Y. Ng, A.W. Mohammad Renewable and Sustainable Energy Reviews 2018, 81, 536

[4] K. Qi, B. Cheng, J. Yu, W. Ho J. Alloys and Compounds 2017, 727, 792

[5] M.A.M. Adnan, N.M. Julkapli, S.B. Abd Hamid Rev. Inorg. Chem. 2016, 36, 77

[6] L.V. Tranfiladović, D.J. Jovanović, X. Zhang, S. Ptasińska, N.D. Dramićanin Appl. Catal. B 2017, 203, 740

[7] A. Samanta, M.N. Goswami, P.K. Mahopatra Physica E 2018, 104, 254 
[8] Z. Chen, N. Zhang, Y.-J. Xu CrystEngComm 2013, 15, 3022

[9] R.T. Sapkal, S.S. Shinde, T.R. Waghmode, S.P. Govindwar, K.Y. Rajpure, C.H. Bhosale J. Photochem. Photobiol. B 2012, 110, 15

[10] L. Yu, W. Chen, D. Li, J. Wang, Y. Shao, M. He Appl. Catal. B 2015, 164, 453

[11] Y.Q. Cao, J. Chen, H. Zhou, L. Zhu, X. Li, Z.Y. Cao, D. Wu, A.D. Li Nanotechnology 2015, 26, 024002

[12] Y.M. Hunge, A.A. Yadav, S.B. Kulkarni, V.L. Mathe Sensors \& Actuators B 2018, 274, 1

[13] M.A. Mahadik, S.S. Shinde, Y.M. Hunge, V.S. Mohite, S.S. Kumbar, A.V. Moholkar, K.Y. Rajpure, C.H. Bhosale J. Alloys \& Compounds 2014, 611, 446

[14] M. Lakhdari, F. Habelhames, B. Nessark, M. Girtan, H. Derbal-Habak, Y. Bonnassieux, D. Tondelier, J.-M. Nunzi Epj Appl. Phys. 2018, 84, 2018180227

[15] H. Ma, P.L. Williams, S.A. Diamond Environmental Pollution 2013, 172, 76

[16] K. Hrács, Z. Sávoly, A. Seres, L.V. Kiss, I.Z. Papp, A. Kulovecz, G. Záray, P. Nagy Ecotoxicology 2018, 27,1058

[17] S.M. Kteeba, A.E. El-Ghobashy, H.I. El.Adawi, O.A. El-Rayis, V.S. Sreevidya, L. Guo, K.R. Svoboda Environmental Pollution 2018, 242, 433

[18] F. Wu, S. Cui, M. Sun, Z. Xie, W. Huang, X. Huang, L. Liu, M. Hu., W. Lu, Y. Wang Science of the Total Environment 2018, 624, 820

[19] N. Kaneva, I. Stambolova, V. Blaskov, Y. Dimitriev, A. Bojinova, C. Dushkin Surf. Coat. Technol. 2012, 207, 5

[20] F. Achouri, C. Merlin, S. Corbel, H. Alem, L. Mathieu, L. Balan, G. Medjahdi, M. Ben Said, A. Ghrabi, R. Schneider Materials 2018, 11, 2158

[21] J.L. Yang, S.J. An, W.I. Park, G.-C. Yi, W. Choi Adv. Mater. 2004, 16, 1661

[22] O.A. Fouad, A.A. Ismail, Z.I. Zaki, R.M. Mohamed Appl. Catal. B 2006, 62, 144

[23] J.-Z. Kong, A.-D. Li, X.-Y. Li, H.-F. Zhai, W.-Q. Zhang, Y.-P. Gong, H. Li, D. Wu J. Sol. State Chem. 2010, 183, 1359

[24] A. V. Ghule, B. Lo, S.-H. Tzing, K. Ghule, H. Chang, Y.C. Ling Chem. Phys. Lett. 2003, 381, 262.

[25] H. Yang, S. Xu, L. Jiang, Y. Dan J. Macromol. Sci. 2012, 51, 464

[26] A. Ulyankina, I. Leontyev, M. Avramenko, D. Zhigunov, N. Smirnova Mater. Sci. Semicond. Proc. 2018, 76, 7

[27] M.R. Nath, A.N Ahmed, M.A. Gafur, M.Y. Miah and S. Bhattacharjee J. Asian Ceram. Soc. 2010, 6, 262

[28] M. Mittal, M. Sharma, O.P. Pandey Solar Energy 2014, 110, 386 
[29] O.I. Gyrdasova, M.A. Melkozerova, I.V. Baklanova, L.Y. Buldakova, N.S. Sycheva, V.N. Krasil'nikov, M.Y. Yanchenko Mendeleev Communications 2017, 27, 410

[30] K.P. Ghoderao, S.N. Jamble, R.B. Kale Optik 2018, 156, 758

[31] G. Bandekar, N.S. Rajurkar, I.S. Mulla, U.P. Mulik, D.P. Amalnerkar, P.V. Adhyapak Appl. Nanosci. 2013, 4, 199

[32] I. Kazeminezhad, A. Sadollahkhani J. Mater. Sci.; Mater. Electron. 2016, 27, 4206

[34] R. Marsalek APCBEE Proc. 2014, 9, 13

[35] S.R. Kanel, S. R. Al-Abed J. Nanopart. Res. 2011, 13, 4035

[36] F.M. Omar, H.A. Aziz, S. Stoll Sci. Total Environ. 2014, 468-469, 195 